\title{
Can we rely on biomass for most of the needs of advancing human civilization?
}

\author{
Subhas Sikdar ${ }^{1}$ \\ Published online: 12 September 2020 \\ ○) Springer-Verlag GmbH Germany, part of Springer Nature 2020
}

Fundamental needs of human civilization are fourfold: food, feed, energy, and chemicals and minerals. This litany has remained essentially unchanged since homo sapiens abandoned the hunter gatherer lifestyle and settled down to husband agriculture, domesticate animals, and created safe environments for survival and species proliferation. Few of the vestiges of primitive and medieval practices exist to support present day human existence. For instance, though meat consumption has remained a dominant practice, it is no longer supplied by hunting wild animals; all meat sources are now domesticated. In recent years, biomass utilization has become a designed approach to provide food, feed, energy, and even chemicals. Minerals are the only need that biomass cannot satisfy, obviously. The question naturally arises: are there limits to what we can do with biomass, is there enough biomass to be had, are there global and local limits before we begin to harm the natural ecological support system, and how would we decide on a sustaining optimized utilization?

For food and feed, the answer is obvious. All food and feed, including fish and meat, are ultimately derived from biological resources. For energy, the picture is complex and interesting. Energy is also fundamentally the causative force behind forays into biofuels and chemicals. Early humans used wood and timber for fuel and construction leading many early and not so early human settlements, cities, and countries to collapse because of deforestation, soil and nutrient loss, as Jared Diamond has analyzed in extreme details in a landmark book. ${ }^{1}$ The advent of coal, later petroleum and natural gas, as primary sources of energy, replacing timber, provided the boost for sustained improvement in income, standard of living across the globe, accelerating urban and suburban infrastructure that stands as a pride of human ingenuity. However, at the same time the genie of environmental degradation was irreversibly unleased. This resulted in air, water, and land pollution, harmful to human health and the environment. The discovery that greenhouse gases such as carbon dioxide, methane, and a few others can be the reason for global warming, and man is responsible in large part, and hence, human ingenuity can be harnessed to reverse the undesired impact, naturally spurred the current efforts on biofuels to potentially replace coal, petroleum, and natural gas for energy and power needs. Biomass is being used in continually improving the technology for fuels such as ethanol to be used for automobiles, and it is also being seriously researched for producing power for base stations for supplying to manufacturing, commercial, and domestic needs. The ecological impacts of biofuels such as ethanol have been discussed and debated for quite some time. I am reminded of the famous energy balance debate on corn to ethanol between David Pimentel and Bruce Date in the pages of C\&E News. ${ }^{2}$ In this debate, one side argued that energy derived from ethanol is more than energy consumed in the processing for it; the other side argued the reverse. The debate, however, continued, albeit in more holistic way, on
Subhas Sikdar

subhas.sikdar@gmail.com

\footnotetext{
${ }^{1}$ Diamond, Jared, Collapse (2005), Penguin Books, New York.

2 C\&EN, Dec. 17, 2007, page 12.
}

1 Cincinnati, USA 
biofuels' "far reaching impacts on agro-ecosystems, food prices, government budgets, and consumer prices," along with doubtful reduction in greenhouse emissions. ${ }^{3}$

Biorefineries as a concept has been advanced to show the plausibility of producing not just fuels but also chemicals. The premise is anchored on a few select chemicals that are produced by fermentation but that can lead to a variety of chemicals that are needed in commerce as feedstocks, such as ethylene, levulinic acid, succinic acid as examples. These feedstocks, on further processing, branch into a host of end-use chemicals including polymers. Thermochemical processes involving biomass as a feedstock, including algae, can be designed to produce heat and electricity, and bio-oil as diesel substitutes. Detailed descriptions of chemical processes that can be exploited for this purpose can be found in Sadhukhan et al. ${ }^{4}$ Electricity generation has also been advocated using the concept of co-combustion with coal, as part of an "all of the above strategy."

Very recently innovations on biomass utilization have led to successful commercialization of vegetarian "meat," following continual search for fermentation-based animal protein analogs over past several decades. Much excitement is seen in a few branded products that are currently being used in burgers that taste like meat burgers. The suppliers of such vegetarian "meat" have reached multi-billion-dollar valuations in the US stock market. With this backdrop in mind, I had asked Prof. Alexey Voinov, an environmental ecologist, to consider writing a Perspective article on a comprehensive analysis of the opportunities and limitations of biomass utilization. Technologies will undoubtedly be ready to provide the necessary ingredients of our needs. As innovations work best in relatively free markets, there will of course not be any check on any of the developments mentioned above. Two decades ago, I heard a lecture by a consultant who opined that his calculations showed that just to meet the automotive fuel needs of the US with no fossil sources we would need the entire state of North Caroline for biomass generation for ethanol. We have already seen the impact of corn to ethanol on corn as food. In the urge to find all solutions in biomass, which beyond being limited, will cause all kinds of adverse environmental impacts. As Jared Diamond showed that not always the potential adverse impacts of human endeavors are unanticipated, but nevertheless they happen. So, what is the art of the possible, and how can policy makers be forewarned? This very question is in the Perspective article presented in this issue.

Subhas Sikdar

Editor in Chief

\footnotetext{
${ }^{3}$ Giampietro M., and Mayumi K. (2009), Biofuel Delusion: The fallacy of large-scale agro-biofuel production, Earthscan, London.

${ }^{4}$ Sadhukhan J., Ng KS, and Martinez Hernandez E.(2014), Biorefineries and Chemical Processes, Wiley, West Sussex, UK.
} 